\title{
O setor do imobiliário residencial em Portugal de 2000 a 2013
}

\section{The residential real estate sector in Portugal from 2000 to 2013}

Fernando Oliveira Tavares 1; Luís Gomes Almeida 2.

\section{Resumo:}

1 E-mail: ftavares@upt.pt;

Universidade Portucalense

Infante D. Henrique

2 E-mail:

gomesalmeida@ua.pt

Universidade de Aveiro
Este trabalho tem como objetivo, fazer uma caracterização do setor imobiliário residencial em Portugal entre o ano de 2000 e 2013, designadamente o mercado de apartamentos nas tipologias T2 e T3. O estudo de caso é a abordagem metodológica utilizada neste artigo, o que permite compreender, explorar e descrever os acontecimentos do tema em estudo. É feita uma análise à evolução dos preços médios de avaliação bancária em Portugal Continental para estas tipologias, observando-se comparativamente as áreas metropolitanas de Lisboa, Porto, as Regiões Norte, Centro, Alentejo e Algarve. Quanto ao enquadramento do mercado, são relacionados os valores e evolução da avaliação bancária com alguns indicadores pertinentes a instigarem uma volatilidade na avaliação, tais como a evolução da taxa de juro, crédito às famílias, índice de confiança dos portugueses, investimento direto estrangeiro na habitação, entre outros, considerados como instrumentos essenciais de diferenciação ante o mercado. Apresenta-se uma conclusão sobre a evolução deste mercado em Portugal.

Palavras-chave: Avaliação imobiliária; setor imobiliário; investidor imobiliário.

\begin{abstract}
:
This work has as main goal, make a characterization of the housing sector in Portugal between 2000 and 2013, including the apartment market in types T2 and T3. The case study is the methodological approach used in this article, which allows us to understand, explore and describe the events of the topic under study.

A review of trends in average prices of bank evaluation is made in Portugal for these typologies, comparing the metropolitan areas of Lisbon, Oporto, the North, Centre, Alentejo and Algarve. As the market environment, values and evolution of bank evaluation with some relevant indicators to instigate volatility in the evaluation are connected, such as the evolution of the interest rate, credit to households, the confidence index of the Portuguese foreign direct investment in housing, among other instruments considered essential to differentiate the market. It presents a conclusion about the evolution of this market in Portugal.
\end{abstract}

Keywords: Real estate appraisal; real estate; real estate investor. 


\section{INTRODUÇÃO}

Neste artigo analisa-se a evolução dos valores de avaliação bancária de apartamentos T2 e T3 no mercado português, completando-se com uma comparação dos preços por metro quadrado das Áreas Metropolitanas de Lisboa, Porto, as Regiões Norte, Centro, Alentejo, Alentejo e Algarve, entre o $1^{\circ}$ Trimestre de 2003 e o $4^{\circ}$ Trimestre de 2013, criando um ranking na avaliação e permitindo verificar os riscos associados ao mercado imobiliário.

Os dados utilizados são os registos do Instituto Nacional de Estatística (INE) dos valores unitários $\left(€ / \mathrm{m}^{2}\right)$ de avaliação bancária de habitação por Natureza e Tipologia em Apartamentos, por este ser um produto, dentro do mercado imobiliário mais homogéneo.

Segundo Tavares et al (2012), a avaliação imobiliária tem diferentes contornos na perspetiva do avaliador, sendo uma delas a perspetiva financeira, onde o investidor procura essencialmente diversificar o risco.

O estudo pretende, assim, contribuir para um melhor conhecimento e desenvolvimento desta área no quadro nacional, permitindo perceber-se as regiões mais caras ou vice-versa, podendo antever o que esperar de uma possível compra, o estudo dá também um contributo em colmatar a carência de estudos existentes nesta área no contesto nacional.

\section{METODOLOGIA}

Neste artigo, é feita uma abordagem teórica sobre o setor imobiliário residencial em Portugal entre o ano de 2000 e de 2013, com o objetivo de observar, compreender e descrever os eventos. Desta forma o nosso estudo recai sobre a metodologia de estudo de caso, metodologia esta que segundo Yin (1994), é uma abordagem metodológica de investigação adequada quando se procura compreender, explorar e descrever acontecimentos. Fidel (1992) considera que o estudo de caso tem como objetivo, a compreensão do evento em estudo e ao mesmo tempo desenvolver teorias a respeito do fenómeno observado. Guba e Lincoln (1994) defendem que esta metodologia pretende relatar os factos como aconteceram, proporcionando conhecimento acerca do fenómeno estudado. Também Silva e Sousa (2009), defendem que esta metodologia é a solução a seguir na situação, quando o grau de controlo exercido pelo investigador sobre os eventos não existe e o estudo se centra num fenómeno natural no seu contexto natural. 
Relativamente ao processo metodológico de recolha de dados, à semelhança de Correia e Reis (2011), recorreu-se à pesquisa documental através da internet, do site do INE e do Banco de Portugal, recorrendo a estas fontes de evidência de informação, para obter conhecimento por forma a corroborar o fenómeno em observação.

Posteriormente analisou-se a diferente informação sobre o valor por $\mathrm{m}^{2}$ dos apartamentos, bem como informações e índices macroeconómicos da economia portuguesa. Este processo de recolha de dados permite verificar o conceito de fiabilidade, isto é, o estudo pode ser replicado por outros investigadores que obterão conclusões idênticas.

Consideramos assim que o estudo de caso é a abordagem metodológica que melhor se adequa ao nosso estudo, permitindo compreender, explorar ou descrever os acontecimentos do tema em estudo.

\section{ANÁLISE DOS VALORES DE PORTUGAL CONTINENTAL}

O fraco dinamismo da economia portuguesa nos anos recentes teve um impacto negativo no setor da habitação. A nível da evolução dos preços por $\mathrm{m}^{2}$ dos apartamentos, a Região do Algarve é a única que se valorizou de uma forma continuada até 2007, apresentando depois de 2007 um decréscimo dos seus valores médios de avaliação. Na Região do Alentejo houve uma valorização entre 2003 e o final de 2005 verificando-se uma desvalorização nos últimos anos (Gráfico 1). 
Gráfico 1 - Valores Unitários Médios $\left(€ / \mathbf{m}^{2}\right)$ da Avaliação Bancária de Apartamentos em Portugal Continental (2003-2013).

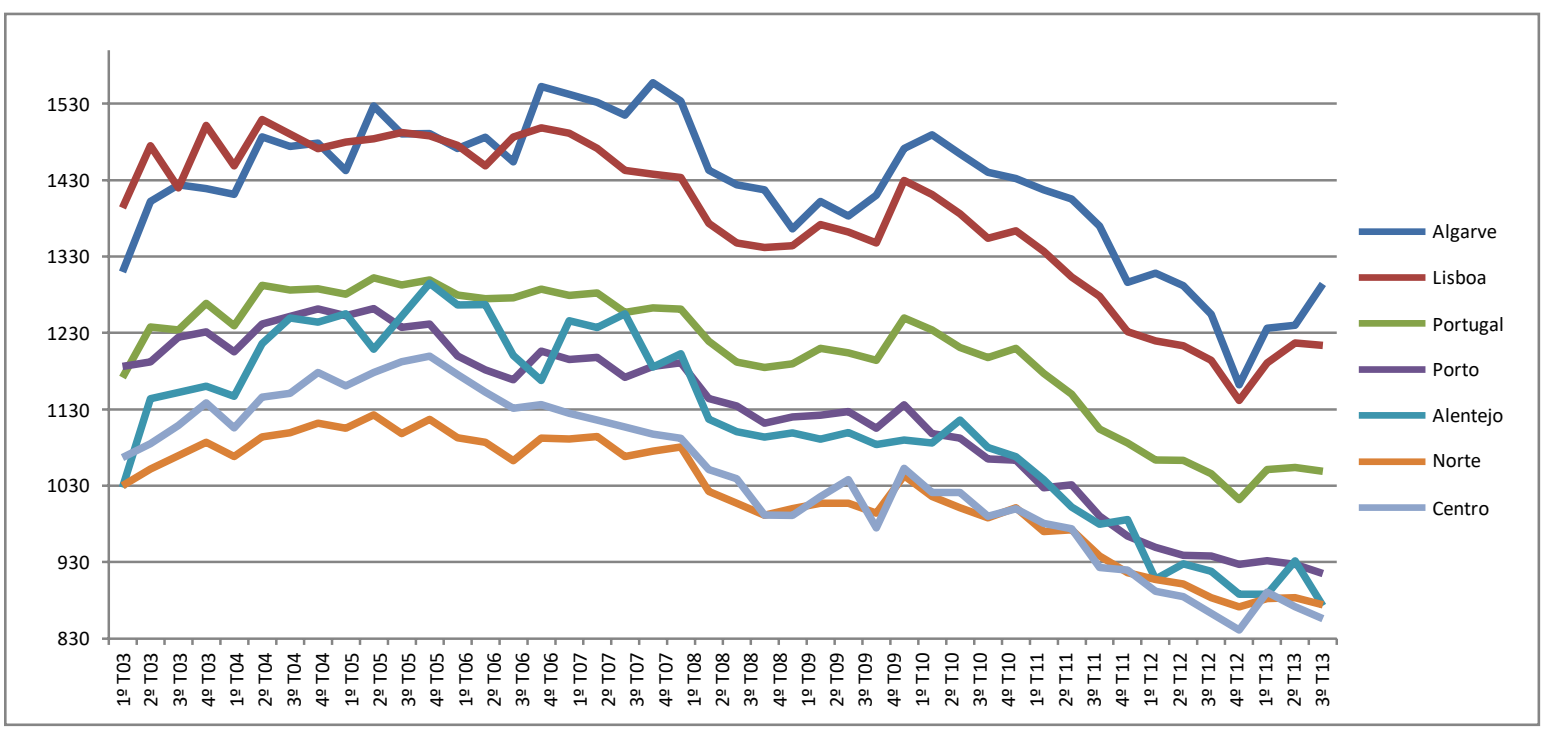

Fonte: Elaboração própria a partir de dados do INE

O Quadro 1 permite comprovar que o Algarve apresenta os valores mais elevados das regiões observadas, seguido pela Área Metropolitana de Lisboa, estas duas regiões apresentam uma média superior à média nacional, que apresenta valores médios de avaliação de $1204,68 € / \mathrm{m}^{2}$.

Quadro 1 - Valores Unitários Médios $\left(€ / \mathrm{m}^{2}\right)$ da Avaliação Bancária de Apartamentos em Portugal Continental (2003-2013).

\begin{tabular}{|l|l|l|l|l|l|}
\hline & Média & Mediana & Mínimo & Máximo & Desvio Padrão \\
\hline Algarve & 1418,43 & 1428,00 & 1162,00 & 1557,00 & 93,616 \\
\hline AM Lisboa & 1382,23 & 1402,50 & 1142,00 & 1510,00 & 104,219 \\
\hline Portugal & 1204,68 & 1226,50 & 1012,00 & 1302,00 & 84,861 \\
\hline AM Porto & 1121,41 & 1140,00 & 915,00 & 1261,00 & 109,514 \\
\hline Alentejo & 1110,18 & 1108,50 & 873,00 & 1295,00 & 121,046 \\
\hline Centro & 1043,84 & 1052,00 & 841,00 & 1199,00 & 104,493 \\
\hline Norte & 1019,80 & 1026,00 & 871,00 & 1123,00 & 76,887 \\
\hline
\end{tabular}

Fonte: Elaboração própria a partir de dados do INE

Abaixo da média nacional, mas com valor próximo temos a Área Metropolitana do Porto, seguida pelo Alentejo e a Região Centro, a região com valores mais baixos é a Região Norte, com valores médios de avaliação de $1019,80 € / \mathrm{m}^{2}$.

Ao analisarmos a evolução da avaliação bancária para os apartamentos T2, conclui-se que nesta situação as duas regiões em destaque são coincidentes com análise anterior. A Região do Algarve apresenta um acréscimo de $207,21 € / \mathrm{m}^{2}$ à avaliação média nacional que é de $1213,27 € / \mathrm{m}^{2}$. De seguida a Área Metropolitana de Lisboa, com uma avaliação de 
$135,50 € / \mathrm{m}^{2}$ superior à média nacional e um hiato entre o valor médio máximo e mínimo de $385,00 € / \mathrm{m}^{2}$.

Gráfico 2 - Valores Unitários Médios ( $\left.€ / \mathbf{m}^{2}\right)$ da Avaliação Bancária de Apartamentos T2 (2003-2013).

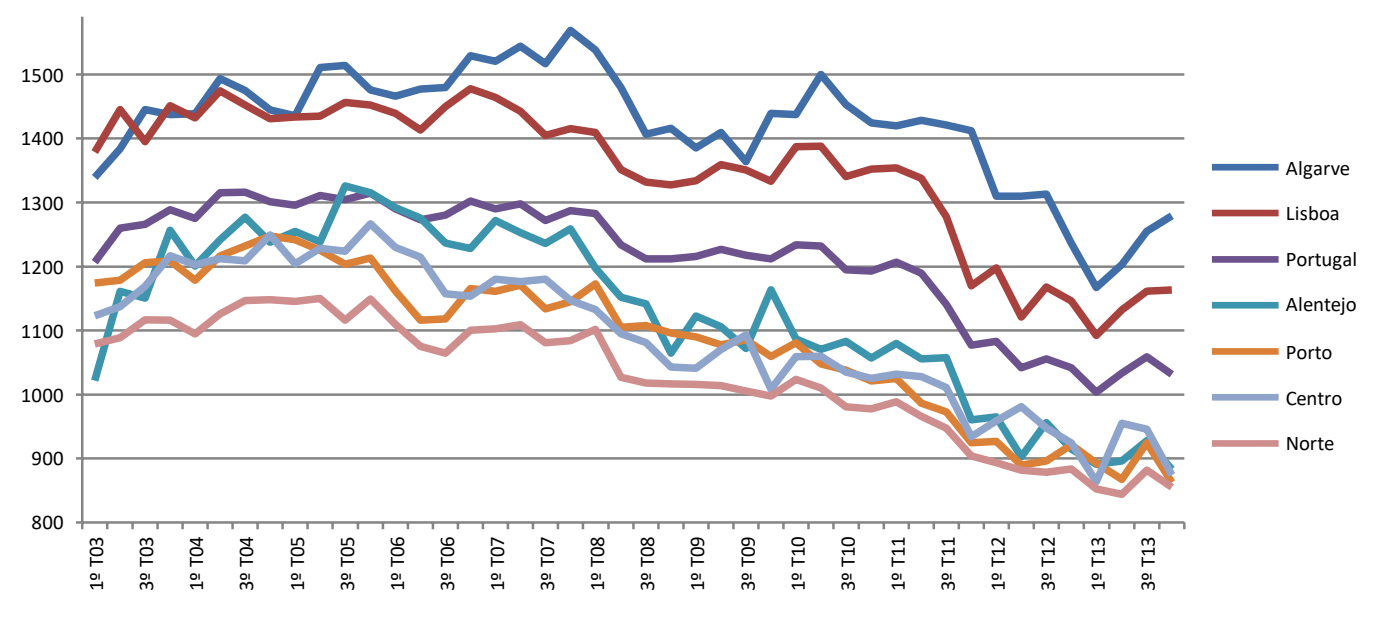

Fonte: Elaboração própria a partir de dados do INE

Contudo a Região do Algarve apresentou uma forte tendência de valorização, até final de 2007, entrando posteriormente em declínio. Os valores médios por $\mathrm{m}^{2}$ da Área Metropolitana de Lisboa entraram em declínio em 2005, apresentando em 2011 uma queda acentuada.

As regiões com valores médios abaixo dos preços do Continente são: Alentejo, Centro, Área Metropolitana do Porto e Norte.

Quadro 2 - Valores Unitários Médios (€/m²) da Avaliação Bancária de Apartamentos T2 (2003-2013).

\begin{tabular}{|l|l|l|l|l|l|}
\hline & Média & Mediana & Mínimo & Máximo & Desvio Padrão \\
\hline Algarve - T2 & 1420,48 & 1437,00 & 1167,00 & 1569,00 & 93,346 \\
\hline AM Lisboa - T2 & 1348,77 & 1383,00 & 1092,00 & 1477,00 & 111,819 \\
\hline Portugal - T2 & 1213,27 & 1233,00 & 1004,00 & 1316,00 & 94,813 \\
\hline Alentejo - T2 & 1126,09 & 1146,50 & 883,00 & 1326,00 & 132,002 \\
\hline Centro - T2 & 1092,66 & 1094,00 & 864,00 & 1267,00 & 109,761 \\
\hline AM Porto - T2 & 1085,91 & 1106,50 & 863,00 & 1248,00 & 116,384 \\
\hline Norte - T2 & 1026,80 & 1025,50 & 844,00 & 1150,00 & 94,922 \\
\hline
\end{tabular}

Fonte: Elaboração própria a partir de dados do INE

A Região do Norte é a que apresenta valores mais baixos de avaliação nos Apartamentos T2, com um hiato entre o valor máximo e mínimo de 306,00 €/ $\mathrm{m}^{2}$. A Região do Alentejo é a que apresenta maior variação entre o valor médio máximo e mínimo, 443,00 €/m², sendo o seu desvio padrão também o mais elevado dentro dos valores médios dos T2.

A explicação para os elevados preços médios de avaliação na Região do Algarve para Apartamentos T2 pode ser fundamentada num estudo do International Tourism Advisers (ILM) (ILM, 2007), onde os potenciais clientes por propriedade são: 41,90\% do Reino 
Unido, 19,88\% de Portugal, 11,01\% da Irlanda, 8,26\% da Espanha, 5,20\% da França e $4,59 \%$ da Holanda, preferindo apartamentos na sua maioria T2 e T3 com clientes numa faixa etária superior aos 45 anos (45,87\% das intenções) e com elevados rendimentos.

É intenção de quem compra habitação no Algarve gozar as férias e arrendá-la no resto do ano, tornando-a assim numa propriedade de rendimento. Quanto à localização preferencial para compra de segundas habitações é de $48,63 \%$ na costa com vista para o mar e 37,08\% na costa. Mas também aqui houve uma quebra na procura nos últimos anos fruto da crise nos mercados financeiros e imobiliários internacionais (ILM, 2007).

O Gráfico 3 apresenta os valores unitários médios de avaliação bancária de Apartamentos T3. Neste gráfico é notório que nos Apartamentos T3 a Área Metropolitana de Lisboa apresenta valores médios superiores à Região do Algarve, o que é uma mudança relativamente aos T2, mas onde a média de Portugal vem de imediato, seguida de perto pela Área Metropolitana do Porto e pela Região do Alentejo, que invertem as posições, vindo posteriormente a Região Centro e por fim a Região Norte que mantém os valores médios de avaliação mais baixos.

Gráfico 3 - Valores Unitários Médios (€/m²) da Avaliação Bancária de Apartamentos T3 (2003-2013).

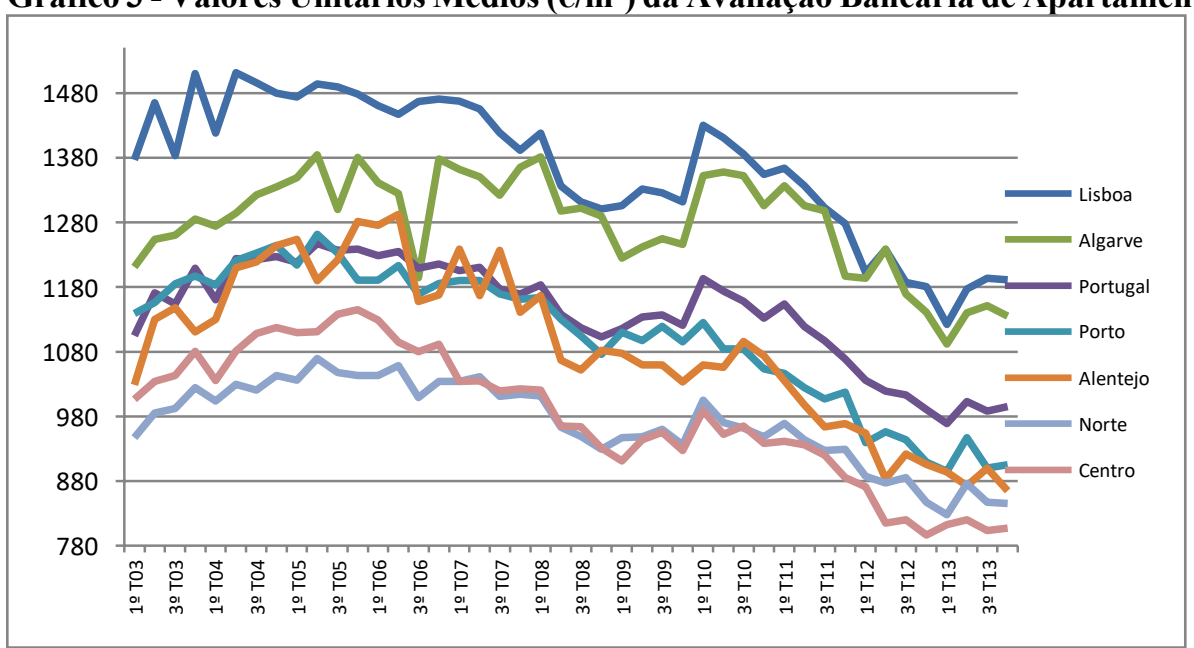

Fonte: Elaboração própria a partir de dados do INE

Nas avaliações de Apartamentos T3 existem mudanças relativamente aos T2, dado que o mercado é ligeiramente diferente. O Apartamento T3 é um modelo mais familiar, por norma as famílias jovens não compram um T3, razão pela qual no mercado dos apartamentos usados os apartamentos T3 são em menor número que os T2. No Quadro 3, verifica-se que as variações entre os valores máximos e mínimos são menos pronunciados. De referir, que este mercado (apartamentos T3) é mais estável, fruto também da estabilidade profissional e familiar de quem compra T3 (Tavares, 2013). O valor médio 
mais elevado das avaliações é na Área Metropolitana de Lisboa com 1367,11 €/m², e uma variação na avaliação de $390,00 € / \mathrm{m}^{2}$, seguida pela Região do Algarve e do valor médio de Portugal que é de $1133,38 € / \mathrm{m}^{2}$.

Quadro 3 - Valores Unitários Médios (€/m²) da Avaliação Bancária de Apartamentos T3 (2003-2013).

\begin{tabular}{|l|l|l|l|l|l|}
\hline & Média & Mediana & Mínimo & Máximo & Desvio Padrão \\
\hline Lisboa - T3 & 1367,11 & 1384,50 & 1122,00 & 1512,00 & 108,184 \\
\hline Algarve - T3 & 1279,34 & 1298,00 & 1092,00 & 1384,00 & 77,633 \\
\hline Portugal - T3 & 1141,43 & 1156,00 & 969,00 & 1247,00 & 80,262 \\
\hline Porto - T3 & 1105,73 & 1127,50 & 895,00 & 1261,00 & 106,358 \\
\hline Alentejo - T3 & 1088,43 & 1080,00 & 865,00 & 1292,00 & 122,708 \\
\hline Centro - T3 & 981,75 & 977,00 & 796,00 & 1145,00 & 103,949 \\
\hline Norte - T3 & 969,84 & 969,50 & 828,00 & 1069,00 & 65,304 \\
\hline
\end{tabular}

Fonte: Elaboração própria a partir de dados do INE

Neste mercado, como já referido anteriormente, a Área Metropolitana do Porto apresenta valores superiores à Região do Alentejo, mas relativamente próximos, já a Região do Alentejo apresenta uma diferença entre o valor máximo e mínimo de avaliação de 427,00 $€ / \mathrm{m}^{2}$, que representa a diferença mais acentuada deste conjunto de dados do INE para Apartamentos T3.

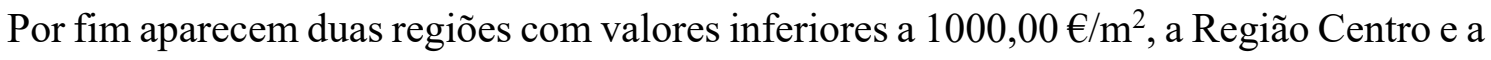
Região Norte.

\section{ÍNDICES MACROECONÓMICOS RELACIONADOS COM O MERCADO DA HABITAÇÃO}

A decisão de adesão à moeda única, para além de eliminar o risco de câmbio face aos outros Estados membros aderentes ao Euro, teve um efeito relevante para as decisões de endividamento do setor privado, em especial para as famílias. Deu-se início à estabilização da inflação e à consequente redução das taxas de juro, favorecida pela crescente competitividade no mercado financeiro e o consequente decréscimo das margens de intermediação bancária.

As taxas de juro, começaram a descer, o que trouxe um incremento ao mercado imobiliário, atualmente a Euribor tem-se mantido abaixo de $0,5 \%$.

Gráfico 4 - Evolução das taxas Euribor a 1 mês, 3 meses e Euribor a 6 meses (valores \%) 

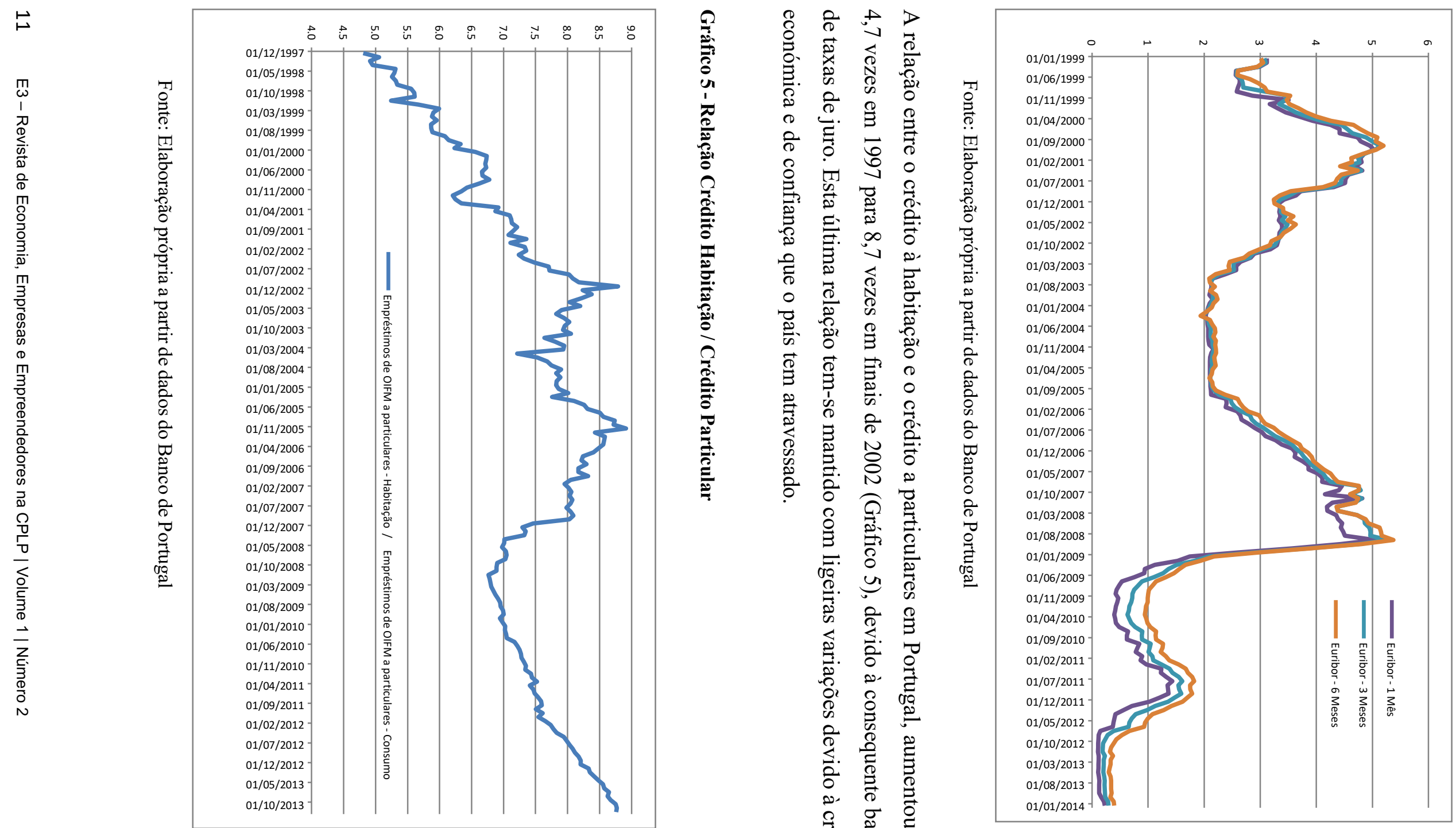

韋. 
Nos anos de 2008 e 2009, a relação entre o crédito à habitação e o crédito a particulares diminuiu, no entanto nos anos de 2010 e 2011 existiu um ligeiro aumento, atingindo em 2012 e 2013 os valores de 2002 e 2005.

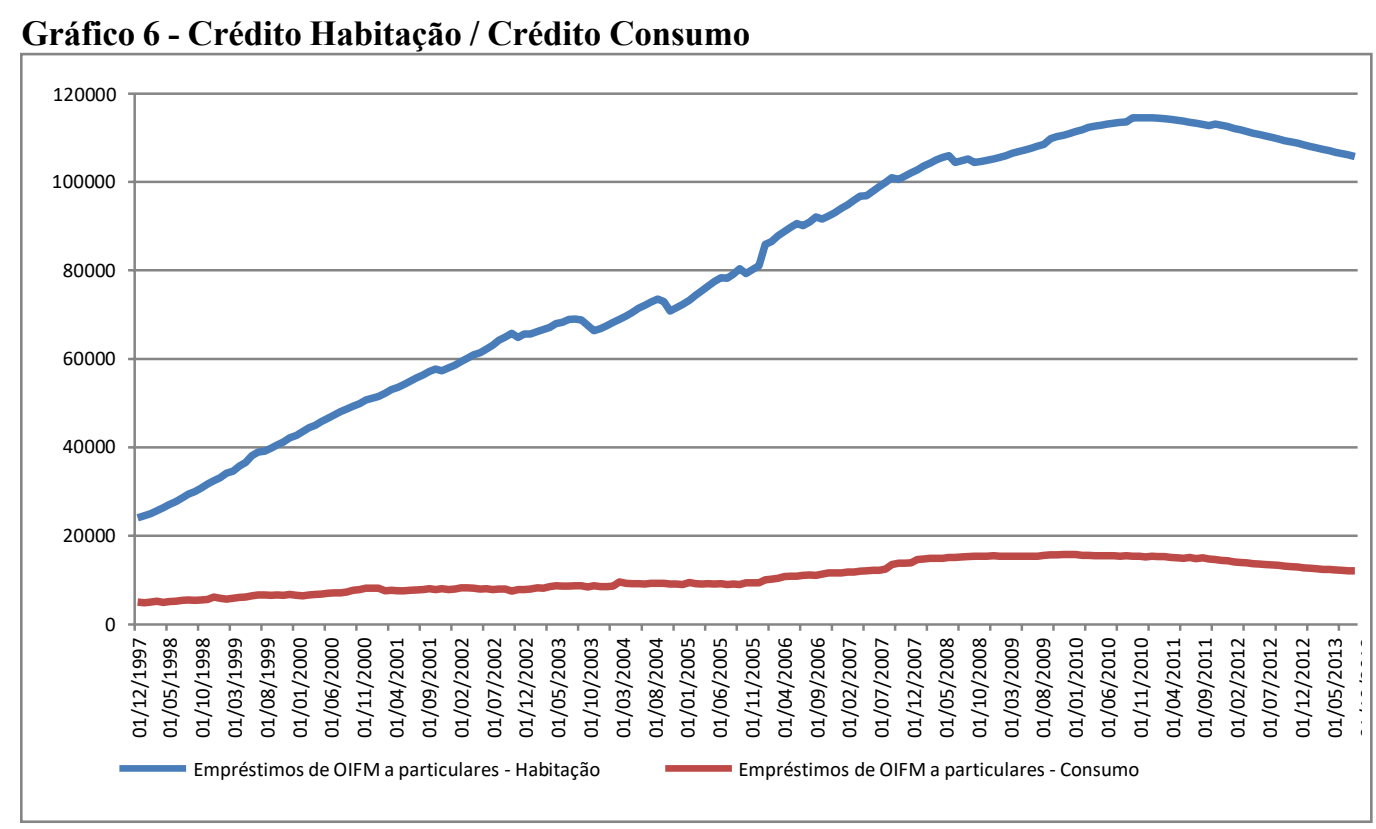

Fonte: Elaboração própria a partir de dados do Banco de Portugal

Sendo a habitação a principal componente da riqueza das famílias, as alterações nos seus preços poderão ter um impacto significativo sobre a perceção das famílias relativamente à sua riqueza e rendimento permanente, bem como sobre as suas possibilidades de endividamento.

Segundo os Relatórios dos Indicadores de Conjuntura do Banco de Portugal, a procura de empréstimos para a aquisição de habitação terá diminuído, essencialmente por via da deterioração da confiança dos consumidores portugueses e das perspetivas para o mercado da habitação. Os fatores determinantes para o aumento da restritividade nos empréstimos à habitação e particulares foram a perceção menos favorável dos riscos, o aumento dos custos de financiamento e restrições do balanço, a diminuição da confiança dos consumidores, a deterioração das perspetivas para o mercado de habitação, antecipando que a estabilidade nos mercados financeiros preveem a continuidade da condicionante negativa tanto a oferta de crédito como o acesso ao financiamento por grosso.

Nos tempos mais recentes há uma queda no crescimento deste valor, devido às subidas dos spreads das taxas de juro e ao facto de haver algumas restrições ao crédito por parte 
das OIFM. O nível de endividamento das famílias portuguesas passou de "relativamente baixo" na década de 1990 para níveis "preocupantes" na 1ª́cada do Século XXI.

Relativamente à evolução do índice de preços, no Gráfico 7, pode-se observar a sua evolução desde 1978 a 2013.

Gráfico 7 - Variação do Índice de Preços no Consumidor \%

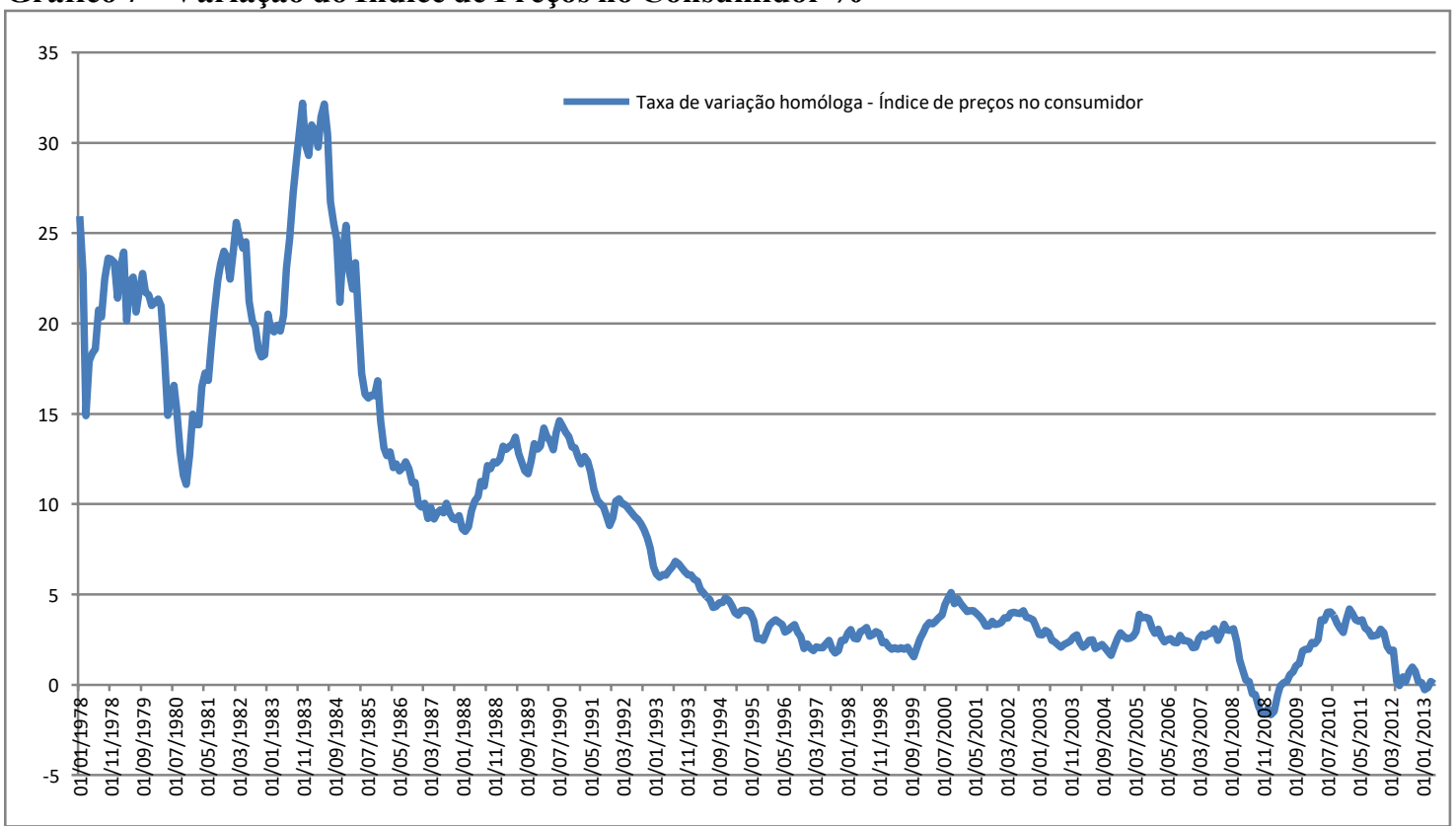

Fonte: Elaboração própria a partir de dados do Banco de Portugal

Na década de 1980 a variação do índice de preços era substancialmente elevado apresentando valores próximos de 35\%, atingindo o valor máximo em 1984, caracterizando-se por uma inflação galopante naquela fase, mas a partir de meados da década de 1990 teve tendência para estabilizar motivada pelos critérios de convergência para a entrada no euro. 
Gráfico 8 - Índice Harmonizado de Preços no Consumidor (Taxa de variação média anual - \%)

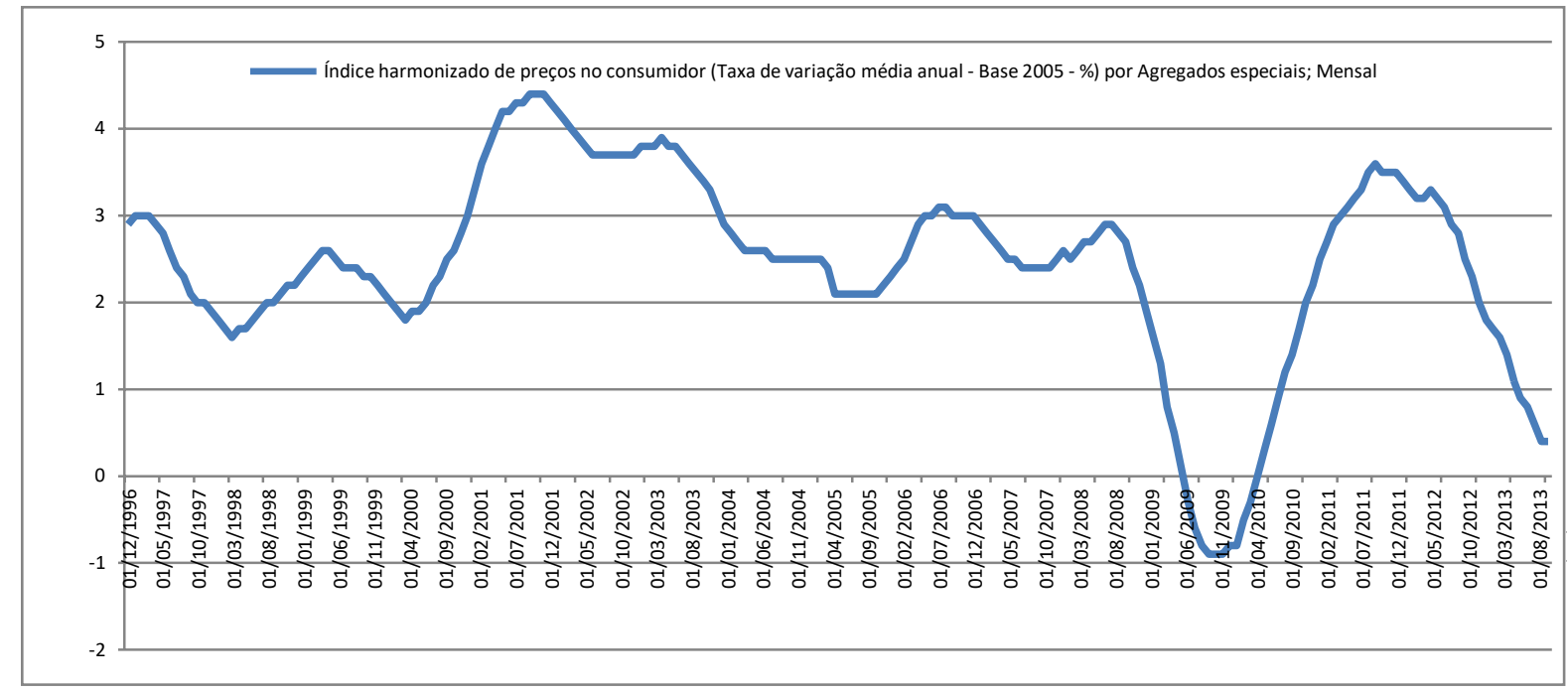

Fonte: Elaboração própria a partir de dados do INE

Nos anos de 2004 a 2006, a taxa de inflação tem-se mantido baixa e estável próxima dos 2\%. Nos últimos dois trimestres de 2009 houve inflação negativa ou deflação, em 2010 e 2011 apresentou valores superiores a 3\%, tendo diminuído em 2012 e 2013 (Gráfico 8).

O Gráfico 9 apresenta as séries relativas aos dos indicadores de confiança dos consumidores portugueses e na construção de Portugal e o indicador de confiança dos consumidores da área euro, os quais evoluem no mesmo sentido. Estas são três séries longas, com início em 1986 até 2013. Nos anos de 1992 a 1995 houve uma grave crise de confiança dos consumidores e de confiança na construção, mas que não se apresentou em níveis tão negativos e tão prolongados como a atual. Em 2011 são apresentados os piores valores desde o início das séries, facto a que não será alheio a crise que o país está a atravessar e à necessidade de ter de cumprir os desígnios da "Troika”. Em 2002 com o cumprimento dos desígnios da moeda única, Portugal passou por uma situação política adversa no final do $1^{\circ}$ trimestre, com eleições legislativas antecipadas e com necessidade, fruto do alargamento da União Europeia, de reformular o modelo de desenvolvimento económico (até então assente na procura interna), a fim de corrigir os desequilíbrios macroeconómicos, tanto a nível das finanças públicas como a nível de estabilidade e crescimento através do Plano de Estabilidade e Crescimento (PEC). 
Gráfico 9 - Índice de Confiança dos Consumidores e Índice de Confiança na Construção

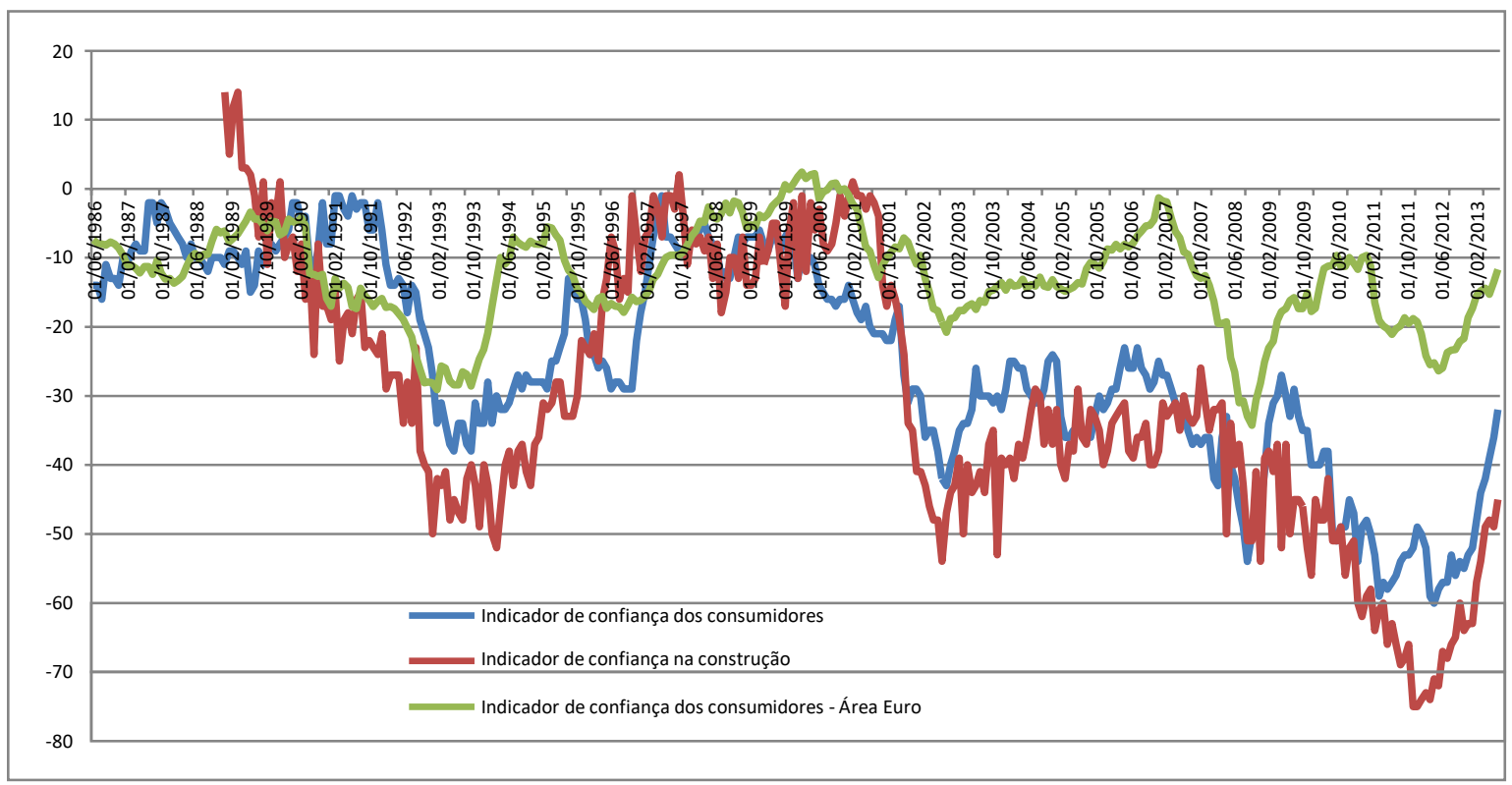

Fonte: Elaboração própria a partir de dados do Banco de Portugal

Assim, em julho de 2002 a taxa normal de IVA passou de 17\% para 19\% a fim de reduzir o défice, mas com impacto pernicioso no investimento. No início do $2^{\circ}$ semestre de 2005 volta a elevar-se de $19 \%$ para $21 \%$ e em 2011 sobe para $23 \%$.

O indicador de confiança na construção decresceu e atingiu valores mínimos logo a seguir a 2002 (facto a que não serão alheias as razões anteriormente apresentadas) caindo também em 2007 e 2008 fruto da crise económica internacional, da crise no Subprime e da falência de um dos maiores bancos de investimento internacional (Lehman Brothers).

A acumulação de capital habitacional, via investimento dos proprietários, constitui aumentos da riqueza das famílias que não se devem a aumentos dos preços reais. Naturalmente que, tais aumentos na riqueza, têm implicações positivas sobre a despesa. Os aumentos dos preços reais da habitação tendem a redistribuir a riqueza entre os agregados jovens e os agregados mais velhos, na medida em que os jovens acumularam menos riqueza habitacional. Sendo que os agregados mais velhos tenderão a possuir maiores propensões marginais a consumir associadas à riqueza habitacional, esse efeito redistributivo vai juntarse ao efeito sobre a despesa agregada (Catte et al, 2004).

A crise de confiança, quer dos consumidores, quer na construção, teve uma queda abrupta em 2002 e prolonga-se até ao presente, no ciclo mais longo da história económica recente 
do país. Percebe-se, então, porque alguns valores de avaliação bancária de apartamentos nos últimos anos se têm mantido ou diminuído.

O Gráfico 10 apresenta a evolução das habitações novas concluídas ao longo dos anos de 1981 a 2013. Em 2002 havia um grande número de habitações novas concluídas, resultado do fim do crédito bonificado à habitação, o que levou a que durante determinado tempo houvesse uma forte pressão para concluir obras que tinham sido iniciadas anteriormente, que apresenta a evolução das licenças de construção de habitação.

Gráfico 10 - Número de licenças de construção de fogos e de habitações novas concluídas

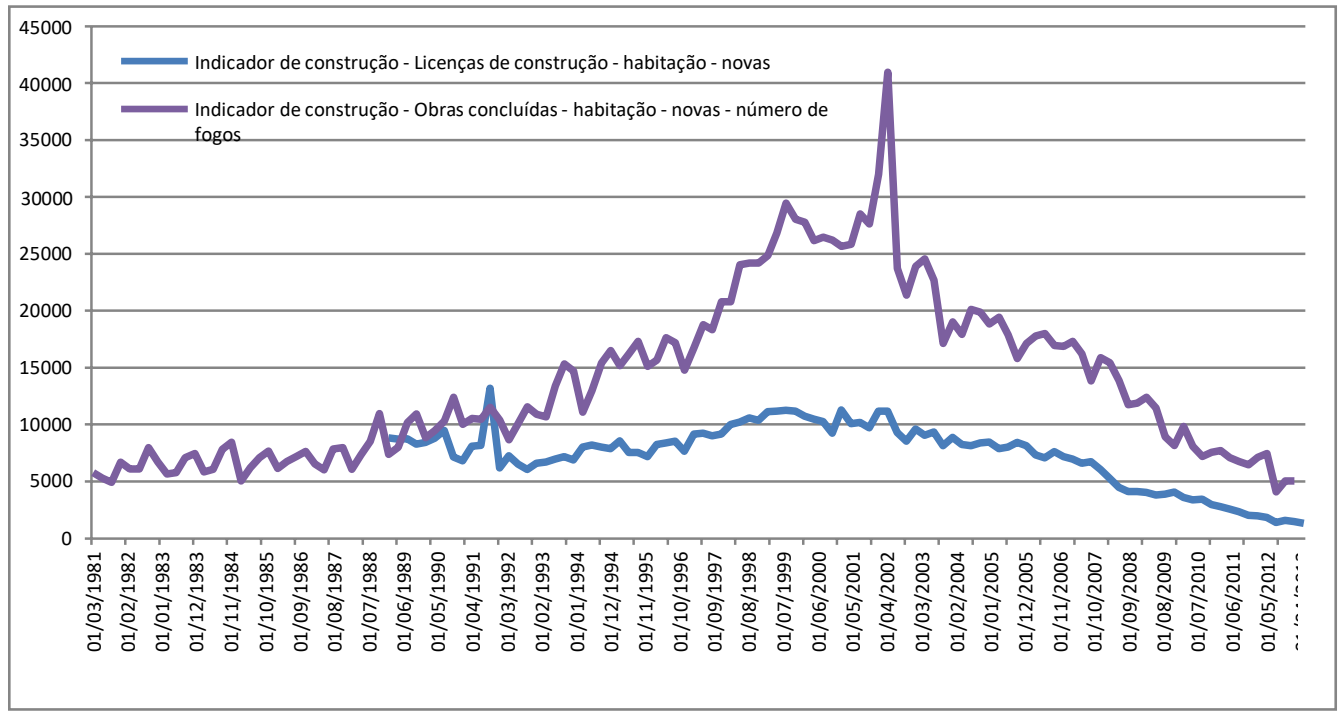

Fonte: Elaboração própria a partir de dados do Banco de Portugal

Segundo um estudo do BBVA ${ }^{1}$ (2006), a construção teria caído gradualmente desde o início da década de 2000, tendo atingido os níveis mínimos dos últimos dez anos, tanto no número de fogos projetados como no número de fogos concluídos, apresentando no final de 2013 valores inferiores a 1989.

\footnotetext{
${ }^{1}$ Banco Bilbao e Viscaya Argentária
} 
Gráfico 11 - Número de edifícios licenciados

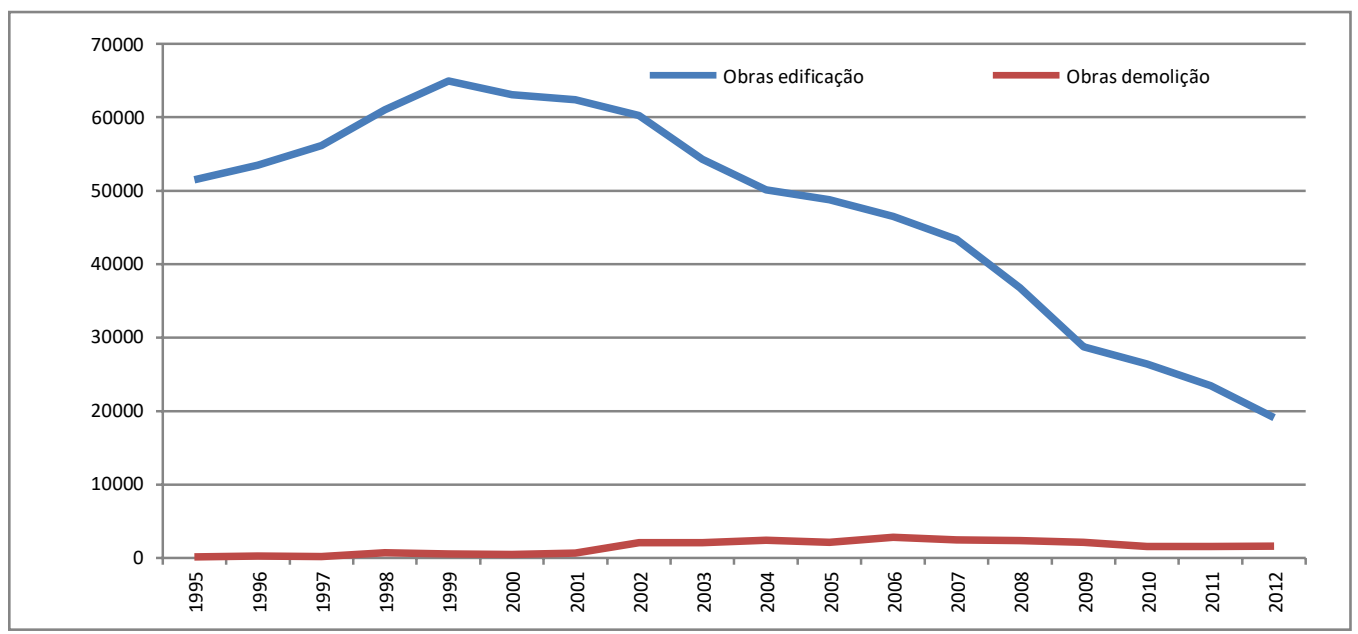

Fonte: Elaboração própria a partir de dados do INE

Em Portugal registou-se uma forte contração do investimento em construção, houve um ajustamento no setor residencial, com uma redução acentuada dos fogos terminados (de mais de 100.000 em 2000, para cerca de 55.000 fogos em 2007) (Banco Santander, 2008).

Como se pode verificar no Gráfico 11 o número de edifícios licenciados caíram de forma abrupta a partir de 2002 (obras de edificação) tendo-se assistido nos anos seguintes a um tímido aumento da requalificação urbana até 2009, mas em 2010 voltou a decrescer e assim se manteve até 2012, ano que apresenta exibe de 30\% das obras realizadas em 1995.

Com o fim do crédito bonificado para compra de habitação própria, em finais de 2002 , houve decréscimo de atribuição de licenças de construção nos anos seguintes, acompanhado de um decréscimo de habitações novas concluídas. De facto, embora talvez um pouco tarde, o mercado começou a aperceber-se que tinha que enveredar pela reabilitação urbana e diminuir a construção de habitação nova. 


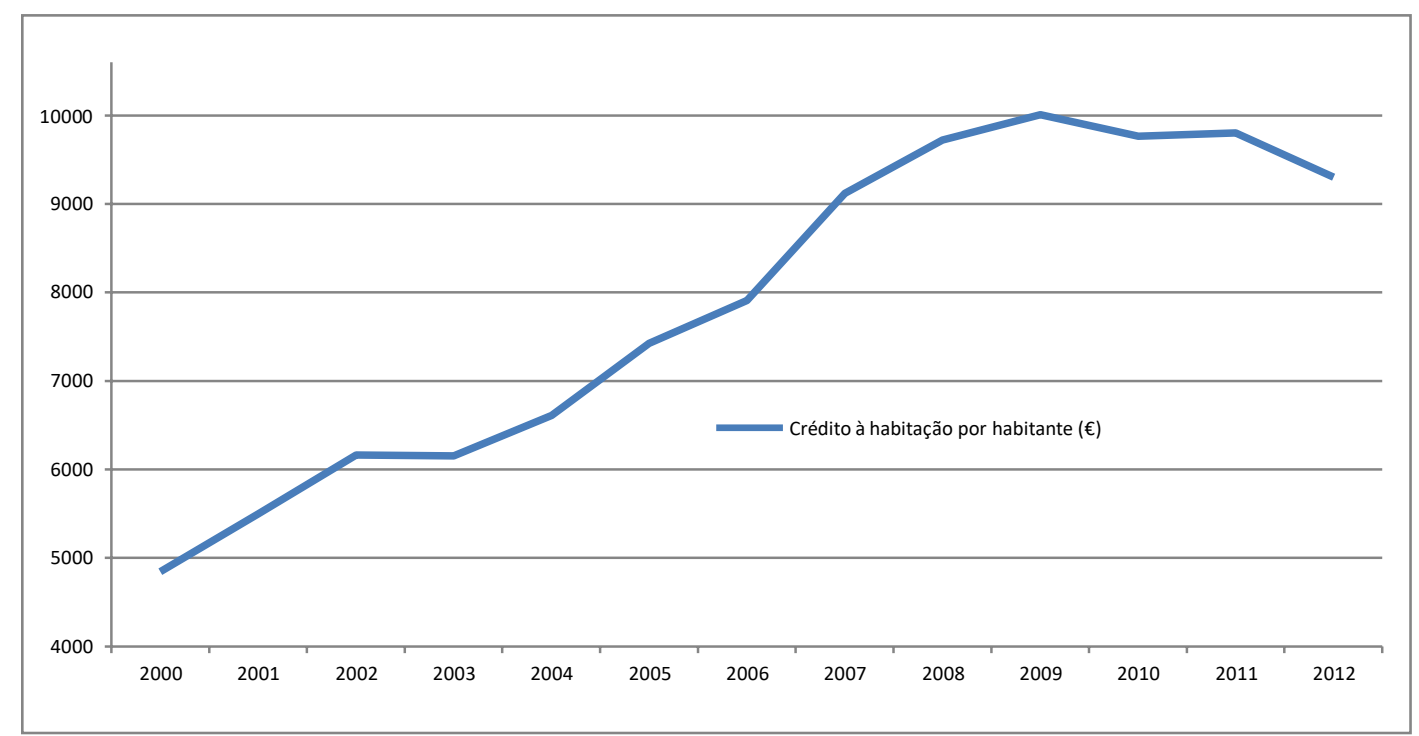

Fonte: Elaboração própria a partir de dados do INE

Como resultado, da crescente dificuldade económica do país a partir de 2002, e das subidas das taxas de juro em 2005, têm aumentado os créditos de cobrança duvidosa ao consumo, mas duma forma mais elevada à habitação.

O crédito à habitação por habitante, conforme se apresenta no Gráfico 12 , tem verificado uma tendência crescente, fruto de recurso ao crédito baseado nos novos instrumentos (seguros e outras garantias) e também no aumento do crédito malparado.

Como é visível no Gráfico 13, os créditos de cobrança duvidosa por finalidade de habitação têm aumentado, de forma substancial, parecendo só a partir de 2013 querer estabilizar, apresentam valores que levam a concluir que numa década o seu nível mais que quintuplicou no crédito de cobrança duvidosa na habitação e sextuplicou para o consumo. 


\section{Gráfico 13 - Empréstimos das OIFM - Créditos de cobrança duvidosa}

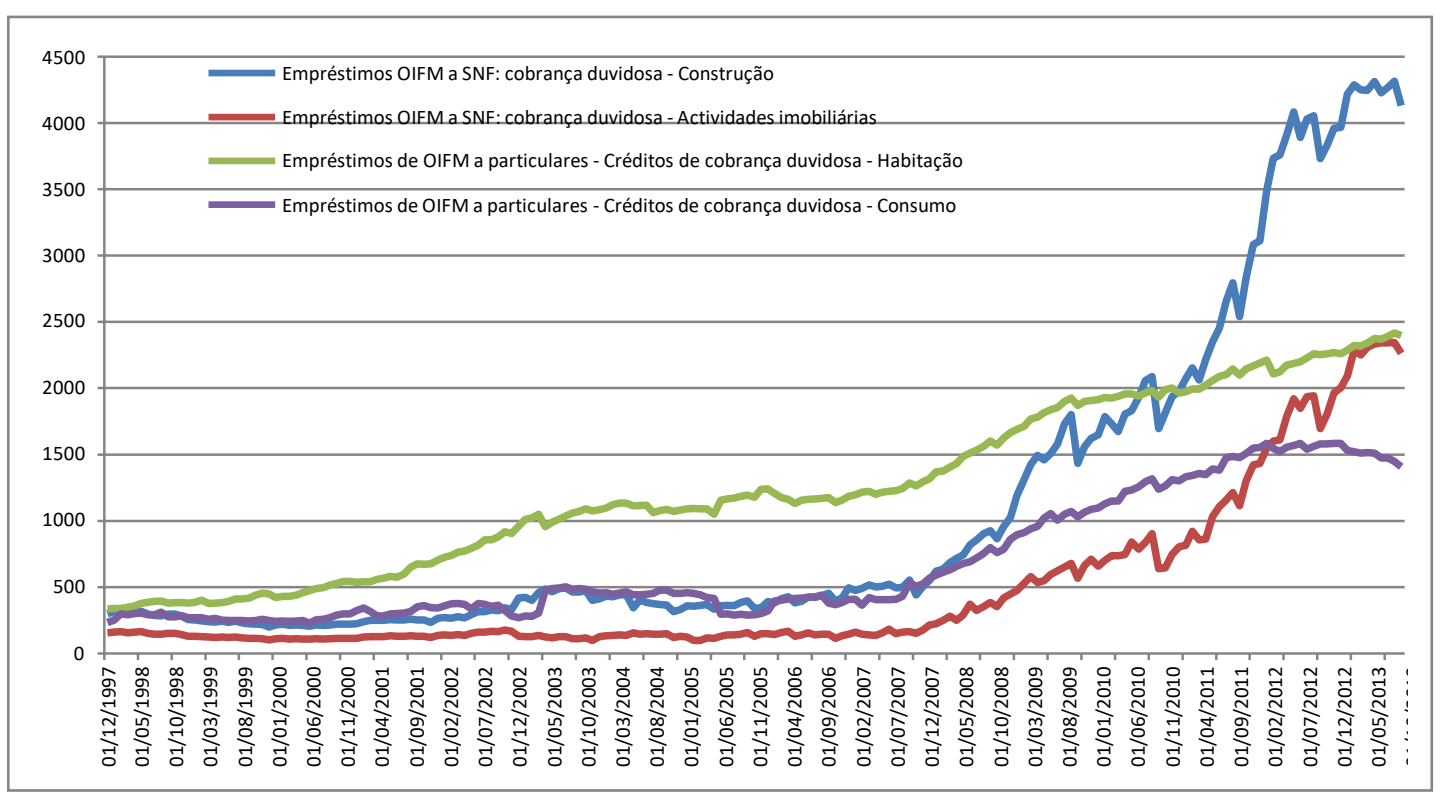

(Valores em $10^{\wedge} 6$ Euros)

Fonte: Elaboração própria a partir de dados do Banco de Portugal

Existe uma maior sensibilidade das famílias, nas suas decisões de consumo, motivada pelo forte crescimento do seu endividamento, o que as torna mais vulneráveis a diversos tipos de choques. Assim, e para além de características estruturais próprias de cada mercado da habitação e do seu financiamento, temos as flutuações no rendimento das famílias, nos preços da habitação e nas taxas de juro.

Em primeiro lugar, o comportamento do rendimento das famílias está altamente dependente da situação económica em termos de desemprego. Um elevado endividamento das famílias e a existência de níveis elevados de serviço da dívida aumentarão a difículdade das famílias confrontadas com situações de desemprego, o que amplificará os efeitos de um choque negativo sobre a economia.

Em segundo lugar, um maior endividamento das famílias, e em que a habitação assume uma fatia significativa da dívida, tornará o setor das famílias mais exposto a quedas nos preços da habitação. A habitação constitui para muitas famílias o seu maior ativo, significando a sua aquisição uma das principais, se não a principal, aquisição ao longo da vida. Ora, o impacto principal da queda dos preços da habitação poderá ser a diminuição dos níveis de confiança dos consumidores, levando a menores despesas de consumo. 


\section{Gráfico 14 - População ativa e emprego total}

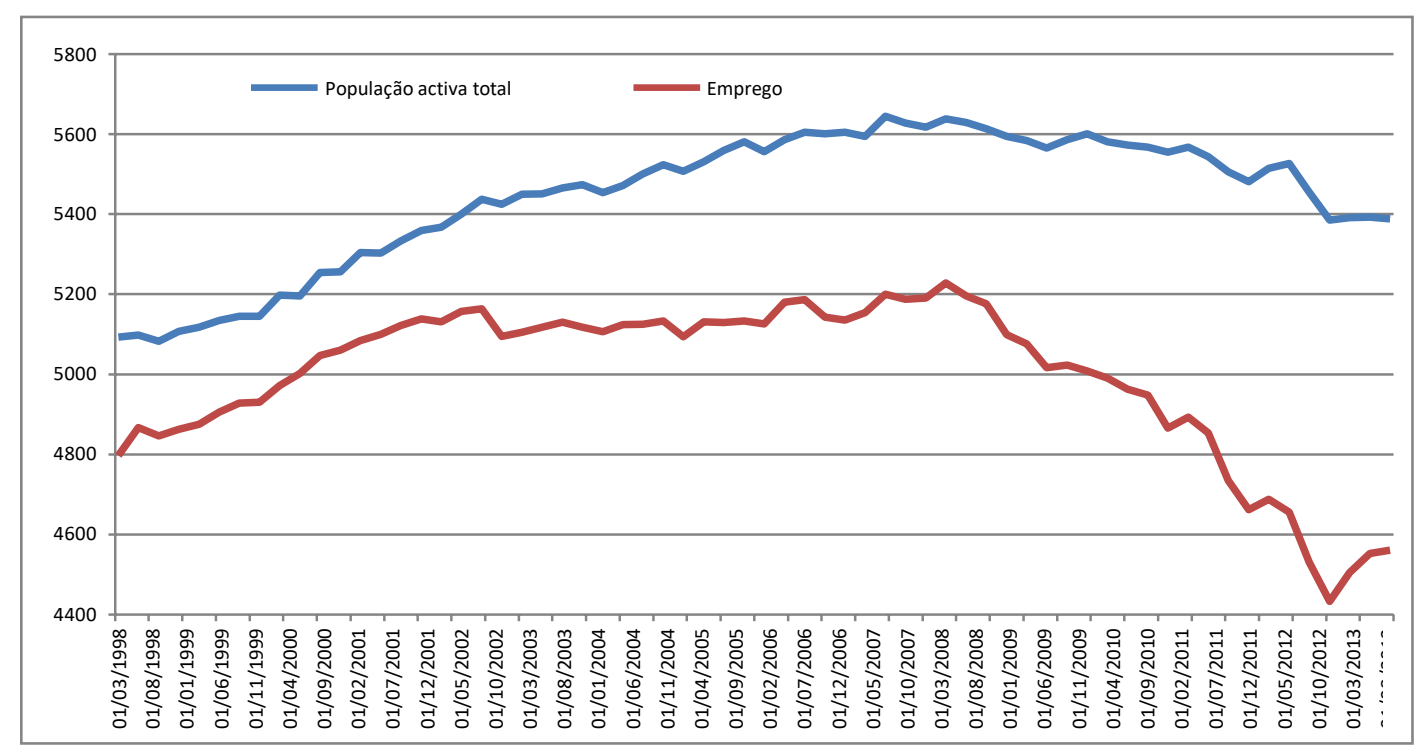

(Valores em 10^3 Unidades )

Fonte: Elaboração própria a partir de dados do Banco de Portugal

Em terceiro lugar, temos um efeito fundamental que deriva de alterações nas taxas de juro, na medida em que as taxas dos empréstimos poderão reagir de modo diferenciado, dependendo do que acontece à curva de rendimentos.

A população ativa em Portugal aumentou do ano de 1998 a 2007, mas diminuiu nos anos mais recentes, como pode ser observado no Gráfico 14, mas o nível de emprego têm diminuído fortemente nos anos recentes, o que afeta o nível de rendimento das famílias e a disponibilidade monetária para a aquisição de habitação. Apesar da população ativa total e do emprego terem estabilizado em 2013, o nível de emprego é o mais baixo de sempre.

A taxa de desemprego de jovens (até aos 24 anos), tem verificado uma tendência de crescimento (Gráfico 15), apresentam valores superiores a 40\%, é uma das taxas mais elevadas da União Europeia, afeta a entrada no mundo do trabalho e atrasa a independência financeira dos jovens, que permanecem até mais tarde na casa dos pais e adiam a compra da nova casa, dá origem a emprego precário e leva a que a compra de casa se torne muitas vezes no maior negócio da vida das famílias. Esta geração, com elevada formação, tem emigrado, deixando de constituir família e procurar habitação em Portugal. Este facto exige uma análise cuidada e leva à constatação de um crescimento na tendência para o arrendamento, que teve algum incremento através de incentivos no ano de 2012. 
Gráfico 15 - Taxa de desemprego

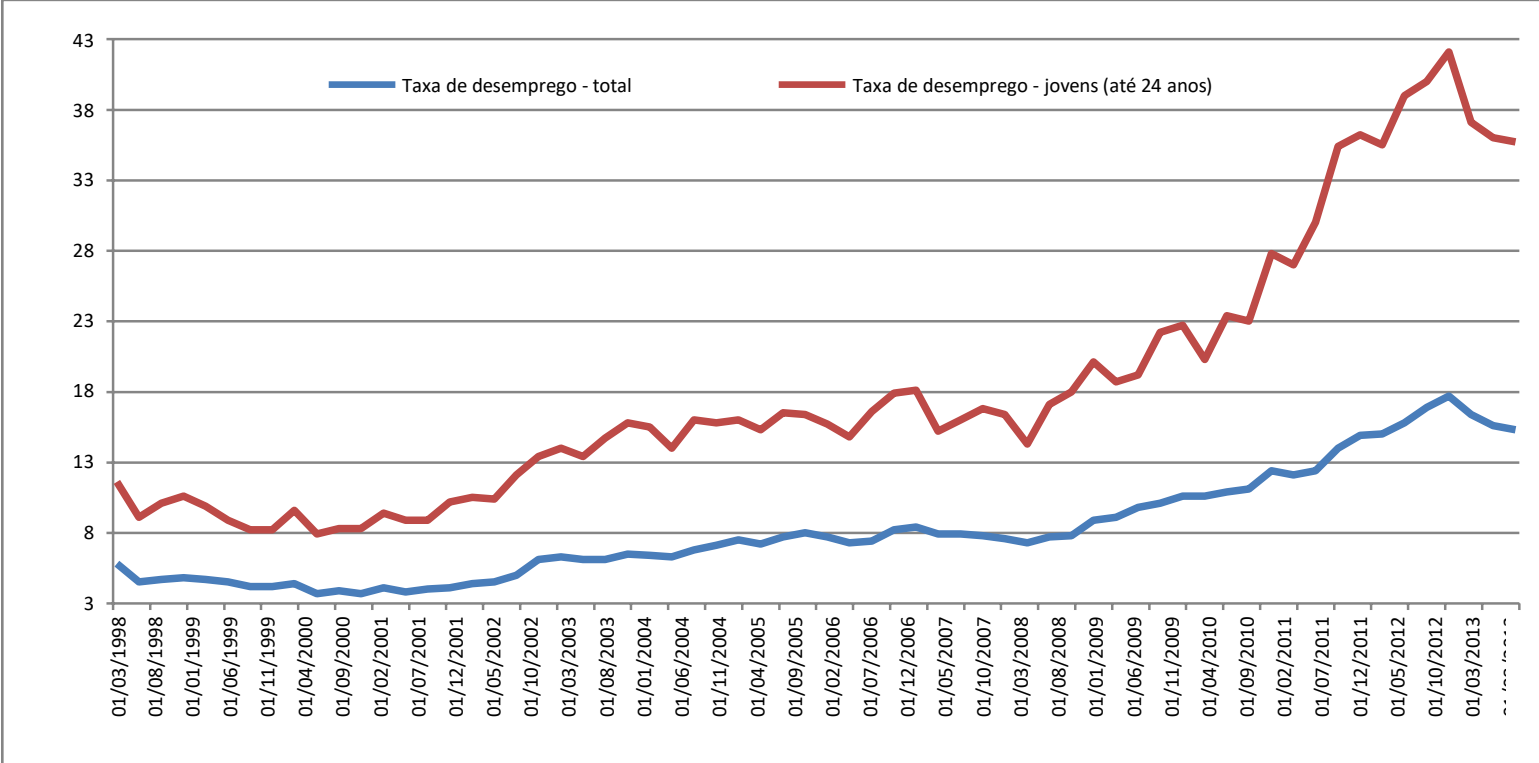

Fonte: Elaboração própria a partir de dados do Banco de Portugal

Desde o ano de 1998 que o saldo da Balança de Transações Correntes (BTC) apresentavase com valores negativos com a exceção num trimestre do ano de 2003, mas onde é visível uma tendência negativa de crescimento até final de 2009 (Gráfico 16). Esta tendência foi agravada pelo nível de preços dos combustíveis, que ajudaram a delapidar as finanças públicas e uma moeda única que se manteve-se excecionalmente elevada, o que dificultou as exportações portuguesas. Há uma forte tentativa de correção do saldo da BTC nos anos de 2011 a 2013.

\section{Gráfico 16 - Saldo da Balança de Transações Correntes}

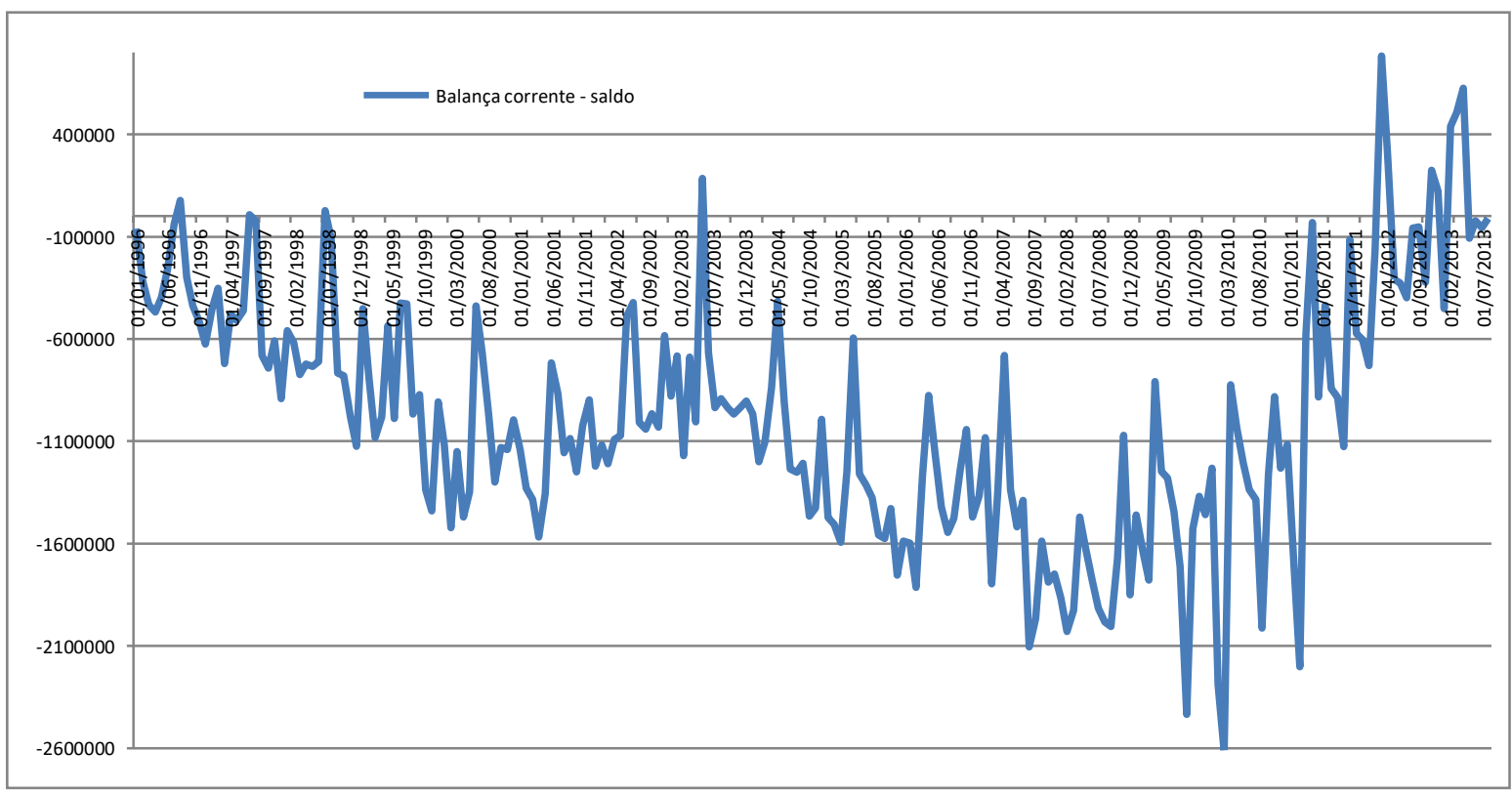

Fonte: Elaboração própria a partir de dados do Banco de Portugal 
Certo é que um país que mantém desequilíbrios a nível do saldo da BTC demonstra problemas estruturais, que levam normalmente muitos anos a serem corrigidos, o que leva a concluir que não havendo produção de riqueza menor será o rendimento das famílias, o que diminuirá o investimento em habitação.

O investimento estrangeiro em Portugal em imobiliário - habitação (Gráfico 17) teve do ano 2000 e até finais de 2007 um crescimento. Este teve impacto no crescimento dos preços da habitação, especialmente no Algarve e na Área Metropolitana de Lisboa, devido ao aumento da procura. Durante o ano de 2008 houve uma forte quebra, relacionada com a crise nos mercados mundiais e manteve-se a níveis baixos até meados de 2013.

Gráfico 17 - Valor líquido das operações de aquisição/alienação, por investidores não empresariais

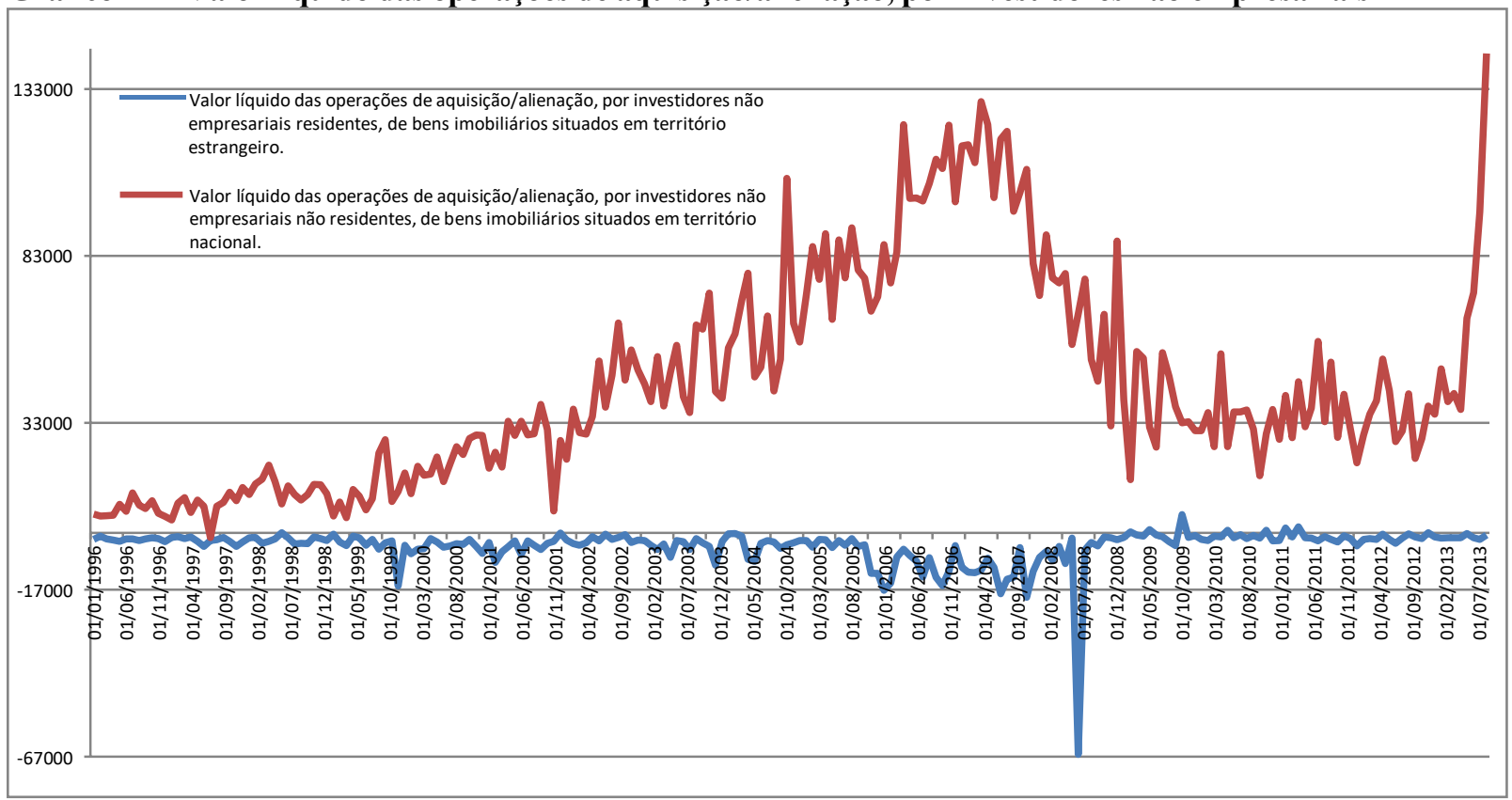

(Valores em 10^3 Euros )

Fonte: Elaboração própria a partir de dados do Banco de Portugal

No segundo semestre de 2013 há um forte crescimento, em nosso entender devido aos vistos gold para quem comprar imóveis com investimento mínimo de 500.000,00 euros.

O Gráfico 18 apresenta a evolução da taxa de crescimento do Produto Interno Bruto (PIB) em Portugal. Entre os anos de 1996 e 1999 houve uma tendência de crescimento, mas de meados de 1999 a meados de 2003 houve uma forte queda, o que coincide com os outros ciclos dos gráficos apresentados anteriormente. A partir do primeiro trimestre 
de 2005, e até ao primeiro trimestre de 2007, houve uma tendência de crescimento. Em 2012 os indicadores apontaram para um crescimento negativo próximo dos 3\% havendo uma recuperação em 2013.

Segundo o estudo do BBVA (2006), Portugal, nos últimos anos e de forma consecutiva, apresenta uma taxa de crescimento inferior à Zona Euro, o que significa um retrocesso no processo de convergência. No entender dos autores deste estudo, a baixa taxa de crescimento do PIB nos anos até 20006 deveu-se fundamentalmente à quebra da procura interna.

Segundo St. Aubyn (2007), em apenas oito anos (1995-2003) o endividamento das famílias portuguesas passou de $54 \%$ para $124 \%$ do seu rendimento disponível. Para este autor a expansão da segunda metade da década de 1990 foi caracterizada por um aumento acentuado do consumo privado, impulsionado pelas baixas taxas de juro, pelo menor recurso ao crédito, pelo rendimento das famílias e pelas expectativas de rendimentos futuros mais elevados. Como explicado pelos modelos macroeconómicos de otimização intertemporal, as famílias tiraram partido das condições mais favoráveis e aumentaram a sua exposição ao crédito. A este endividamento das famílias deve-se adicionar o endividamento do Estado, que se vê refletido no endividamento externo da economia e na intervenção necessária em 2011 por parte da União Europeia e do Fundo Monetário Internacional.

Gráfico 18 - Evolução da taxa de crescimento do Produto Interno Bruto em Portugal

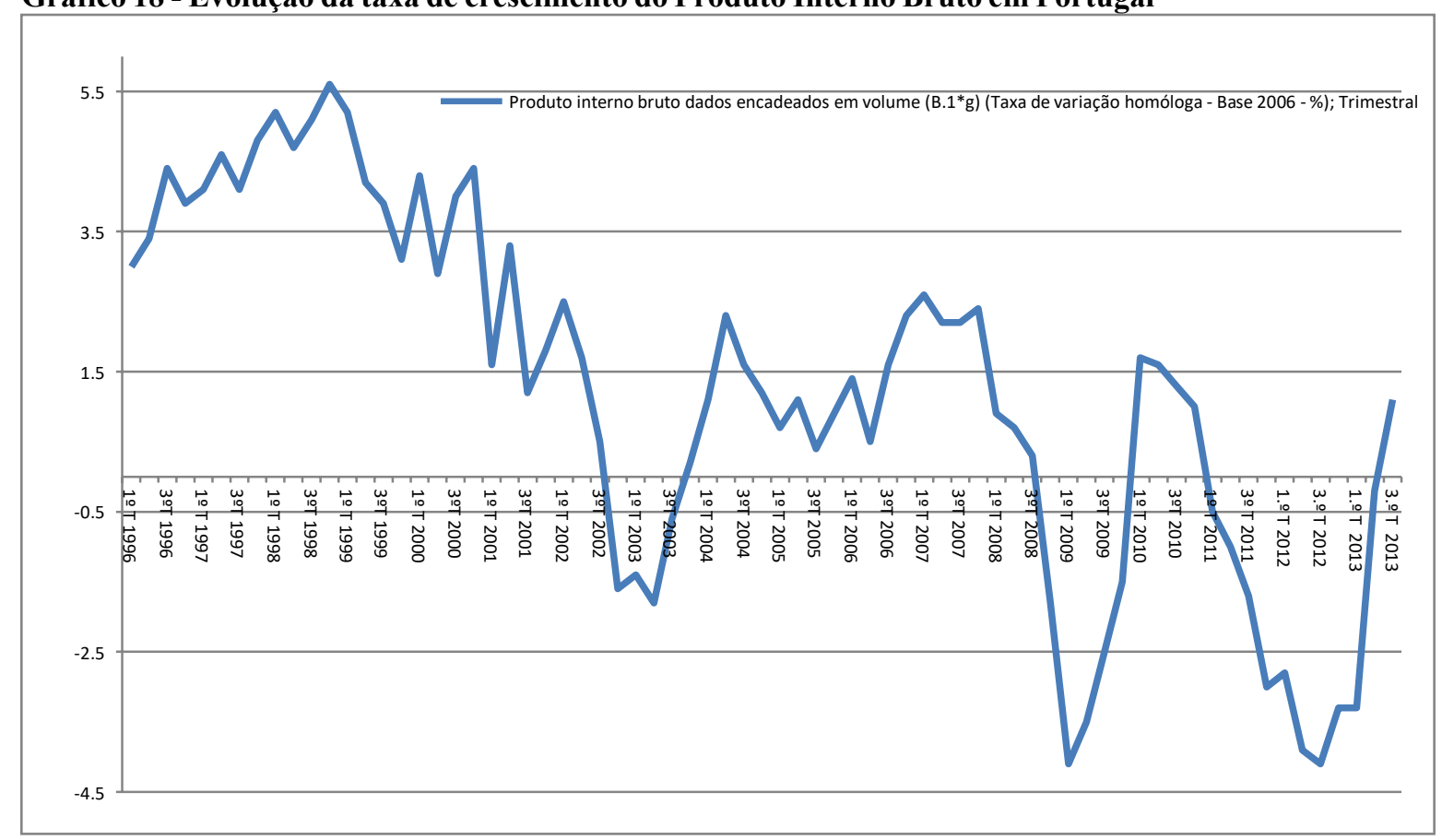

Fonte: Elaboração própria a partir de dados do INE 
A retoma da economia portuguesa dependerá do sucesso do processo de consolidação orçamental, o que implicará uma variação do consumo público. $\mathrm{O}$ investimento em habitação e o crescimento do consumo das famílias estagnou. De salientar que o stock habitacional português evoluiu de forma acentuada ao longo dos anos até 2008 pelo que, acrescendo o facto das restrições orçamentais das famílias terem aumentado, eliminou a carência de oferta que era observada no início da década de 1990.

O sucesso da retoma dependerá da evolução positiva da produtividade das empresas, apoiada em investimentos qualitativamente superiores quer em capital físico quer humano, permitindo aumentos salariais e de rendimentos significativos, que sustentarão o consumo das famílias em níveis mais elevados.

\section{CONCLUSÃO}

Portugal passou de uma situação de carência de habitação que se fazia sentir no início da década de 1990 para uma situação em que o mercado não aceita um número de fogos igual ao dessa época. No mercado foram lançados cerca de 100.000 fogos entre 2000-2002 e em 2009 o mercado só aceitava 55.000 fogos. Hoje é um mercado residual, com valores inferiores aos do início da última década do século passado.

Em termos de preços do $\mathrm{m}^{2}$ de avaliação, com a exceção da Região do Algarve e da Área Metropolitana de Lisboa, os preços não têm sofrido grandes tendências para a valorização, tendo-se assistido mesmo a uma forte queda em 2009 que se prolongou até 2012.

Devido à atração turística, principalmente internacional, o mercado do Algarve valorizou-se de forma substancial até 2007, o que não foi acompanhado com a mesma amplitude pelo mercado nacional. As diferenças máximas entre os valores de avaliação máximos e mínimos são detetados nos concelhos ou regiões onde abundam externalidades na habitação, sejam elas do mar, rio ou monumentos históricos.

Os valores de avaliação por metro quadrado decrescem dos apartamentos T2 para os Apartamentos T3, cumprindo assim a regra de que quanto maior área menor será o valor por $\mathrm{m}^{2}$, isto em termos médios, mas não esquecendo que a qualidade será um fator importante, (mantendo as outras características como por exemplo a localização iguais). 
As taxas de juro baixas, contribuíram para o aumento do crédito à habitação e ao consumo, havendo o sentimento atual de um país endividado, onde o crédito malparado é preocupante, apesar de haver garantias reais subjacentes, o que não acarreta grandes problemas de solvabilidade para os bancos.

Preocupante é o índice de confiança na construção, que é idêntico ao índice de confiança dos consumidores. Ambos apresentam-se com valores substancialmente baixos desde 2002 e será uma das razões para a quebra na construção de fogos, bem como o apetite para a cobrança dos impostos sobre o património que se tem evidenciado ultimamente. $\mathrm{O}$ crédito mal parado às empresas de construção apresentava os valores mais elevados de sempre no final de 2013.

Um dos aspetos perniciosos para a evolução positiva do mercado imobiliário é a taxa de desemprego dos jovens (até 24 anos), o que faz com que se retarde a compra de habitação pelos jovens e retraia o mercado. Alguns incentivos surgiram para o arrendamento, o que veio incrementar um pouco o mercado de arrendamento.

Só poderá haver um crescimento futuro sustentado com uma melhoria do ambiente macroeconómico do país. As famílias endividaram-se na expectativa de melhorias salariais e de outro tipo de rendimentos futuros que na realidade não aconteceram, ficando a necessidade de pagamento da fatura dos juros.

O mercado imobiliário em Portugal apresenta-se sombrio e o sucesso da retoma dependerá da evolução positiva da produtividade das empresas, da melhoria das qualificações que permitam atrair novos investimentos de qualidade superior, onde os aumentos de salários se traduzam em aumentos de rendimentos significativos, que sustentarão o consumo e o investimento das famílias.

\section{Bibliografia}

- Aubyn, M. (2007). Evolução macroeconómica portuguesa e o consumo, endividamento e investimento das famílias. Revista Confidencial Imobiliário, fevereiro: p. 23-26. 
- Banco Santander. (2008). Estudo sobre a Banca e o Setor da Construção em Portugal e Espanha. Lisboa,.

- BBVA - Banco Bilbao Viscaya Argentaria (Portugal), SA., (2006). Situação Imobiliária Portugal. Lisboa.

- Banco de Portugal, (2010). Boletim Económico. Primavera, 16(1).

- Banco de Portugal, (2013). Boletim Económico. Inverno, 19(4).

- Banco de Portugal, (2014). Inquérito aos Bancos sobre o Mercado de crédito, Resultados para Portugal. Janeiro.

- Câmara Municipal de Lisboa (2005). Habitação e Mercado Imobiliário na Área Metropolitana de Lisboa, Coleção Estudos Urbanos - Lisboa XXI.

- Catte, P., Girouard, N., Price, R. \& Christophe, A. (2004). The contribution of housing markets to cyclical resilience. OECD Economic Studies, 38(1), 125-156.

- Correia, P., \& Reis, A. (2011). Pesquisa estruturada versus pesquisa em texto livre na seleção de imoveis em sites imobiliários. Revista Portuguesa e Brasileira de Gestão, 10(4), 210.

- International Tourism Advisers, (2007). Residential Tourism Market Intelligence. Lisbon: International Tourism Advisers.

- Fidel, R. (1992). The case study method: a case study. In: GLAZIER, Jack D. \& POWELL, Ronald R. Qualitative research in information management. Englewood, CO: Libraries Unlimited, 238, 37-50.

- Guba, E., \& Lincoln, Y. (1994). Competing paradigms in qualitative research, In: Denzin, Norman; Lincoln, Yvonna (Ed) (1994) Handbook of Qualitative Research, Thousand Oaks, CA: SAGE Publications, 105-117.

- Silva, S., \& Sousa, M. (2009). Consórcios internacionais de empresas de construção civil: o caso da Mota-Engil. Revista Portuguesa e Brasileira de Gestão, 8(2), 51-63.

- Tavares, F., Moreira, A., \& Pereira, E. (2012). Avaliação Imobiliária: dois casos da importância das vistas como externalidades. Revista Portuguesa e Brasileira de Gestão, 11(4), 02-13.

- Tavares, F. (2013). Avaliação Imobiliária: Entre a ciência da Avaliação e a Arte da Apreciação. Vida Económica, Porto.

- Taylor, J. (2007). Housing and Monetary Policy. NBER Working Paper No. W13682 (December). Available at SSRN: http://ssrn.com/abstract=1077808.

- Yin, R. (1994). Case study research: design and methods. 2. ed., Applied Social Research Methods Series, vol. 5, Sage Publications. 